\title{
1 \\ Alternative decisions, consequences and evaluations
}

\subsection{LEGITIMISATION OF COLLECTIVE DECISIONS THROUGH CONSENSUAL PROCEDURES OR CONSENSUAL OBJECTIVES}

Decisions play an important role in the work of legislators, public administrators, and the courts. Decisions are choices between different courses of action. In order to reach a decision, one needs a decision rule or a decision procedure. Majority decisions in parliaments or referendums are decision-making procedures just as much as the logically deductive subsumption model of the application of the law by the judge, such as customs and traditions - for example, the custom in many parliaments whereby the oldest member presides over the constituent session - or the lottery procedure by which public offices in ancient Greece were filled from among the citizens.

The particular feature of decisions by state bodies is that they do not primarily concern the well-being of the decision-maker himself, but rather that of other people, whose material situation and personal existence is often deeply affected. Furthermore, they are enforced by the state's monopoly on the use of force. Such decisions therefore require a special degree of legitimation to avoid them being perceived as arbitrary and unjust. This legitimation can principally be achieved by two means, either through generally agreed decision-making procedures or through generally agreed objectives.

Assuming that it is possible to formulate objectives for government action which are generally endorsed by citizens, fully taken into account by the decision-maker and sufficiently concrete to clearly guide decisions, such decisions would be generally accepted, irrespective of the nature of the decision-making process. If, however, certain areas of decision-making lack consensus objectives, a democratic procedure, for example, can legitimise the decision, even if many consider it to be problematic in terms of content. Economics can provide answers regarding the efficiency of alternative decision-making procedures, socio-politically desirable goals, and how these goals can be achieved. It can therefore help with the analysis of decisions made by legislators, public administration, and the courts. 


\subsection{IMPACT-BASED JUDICIAL DECISIONS}

Regarding court decisions, economics can be useful if the judge's commitment to law and justice in a civil law country allows for different judgments, for example if a court can either grant the claim to the plaintiff or dismiss the action. For this case of judicial development of the law, which is similar to case law in a common law country where a court must think like a lawmaker, the procedure of a decision made by an individual or by a small panel will convey only little legitimacy, for example through a discourse with the parties involved. Therefore, it is all the more important in such a case that the decision be geared towards agreed notions of justice and goals of the common good. Under no circumstances may a court take into account only the interests of the parties. Even a dispute that appears to be of a purely private nature must be resolved in a way that serves the interests of the community as a whole. For the court's decision settles not only the private dispute between the plaintiff and the defendant. It also shapes future behaviour in the legal community, whose members make their decisions in the shadow of the law.

The further development of the law usually faces several tasks. It must substantiate that the commitment to law and justice need not lead to a clear solution. It must also consider the consequences of alternative decisions, i.e. make decision forecasts, taking into account in particular the effect of a decision on the future behaviour of those to whom the law applies. Microeconomic theory, in particular the economic analysis of law, can often help with this task.

To merely know its likely consequences does not suffice for a decision. Instead, an impact assessment is furthermore required. He who applies the law must know which of the alternative decision results is best in line with public welfare goals, consensual concepts of justice and legal principles. To derive such goals, welfare economics has developed a set of criteria that can be useful for the legal practitioner and that constitute the basis of the economic analysis of law.

It is important to stress that the analysis and the evaluation of the impact of legal decisions are two independent and separate tasks. The first task is an empirical and analytical one, the second is a normative one. Legislation, but especially the further development of the law, must, on the one hand, identify and justify the desired objectives and, on the other hand, explain the empirical-analytical connection between the proposed further development of the law and the desired objective. The next chapter first of all deals with the economic method of impact assessment.

\subsection{EXPLANATION, FORECAST, IMPACT ANALYSIS}

Faced with alternative decision options, one must be able to form an idea of the consequences that a decision is likely to have. In principle, an analysis of the consequences of decisions is no 
different from a scientific explanation. ${ }^{1}$ An explanation always addresses the question "Why is something the case?" According to the widely used Hempel-Oppenheim model of scientific explanation (1948), answering such questions always requires two classes of statements: hypotheses and antecedent conditions.

Let $F$ be the event or the sequence that is to be explained. Then certain singular events, concrete conditions, are mentioned which occurred before or simultaneously with the episode. These are the antecedent conditions, which we denote as $A_{1}, A_{2}, \ldots A_{n}$. In addition to these antecedent conditions, the explanation requires hypotheses, which we shall call $H_{1}, H_{2} \ldots H_{n}$. The event to be explained, $F$, is called the explanandum. The propositions that formulate the antecedent conditions and the hypotheses are called explanans. The difference between an explanation and a prediction is that in the former, the explanandum is known whilst the explanans remains to be found. In an explanation, a previously unexplained but known fact can thus be explained by introducing new, previously unknown hypotheses or antecedent conditions. In a forecast, on the other hand, the hypotheses and antecedent conditions are known, whilst the facts are unknown but can be predicted.

If the public administration bases its decisions on false hypotheses or ignores important antecedent conditions, grave errors can ensue in explaining the facts, as A Sen analysed in the context of the 1943 Bengal famine. ${ }^{2}$ The British colonial administration in India at the time worked with the hypothesis that famines were the result of a food deficit: too little food for too many people. Since a normal harvest was expected in Bengal for 1943, it did not take any special precautions. When reports of a famine arrived in Calcutta, the administration initially rejected them as untrustworthy because there was enough rice. It was only when masses of exhausted and starving people from the surrounding area arrived in Calcutta that the colonial administration reacted, but it clung to its theory regarding a food availability deficit as the cause of famines and now assumed that its information about the availability of grain in Bengal was incorrect. The colonial administration therefore ordered grain from Australia, which arrived many weeks later because of the war in the Pacific. By then the famine had become a catastrophe. In fact, people died whilst the rice depots were full. At the time, due to the war, the port of Calcutta was undergoing major infrastructure investments. Many workers from the region were hired for this, and most of their wages were spent on food - mainly rice. This surge in demand drove up the price of rice. Rice traders interpreted the increase as indication of further price increases in the future and hoarded rice in order to be able to sell it later at a higher profit. This triggered a speculative price spiral and led to further hoarding of grain stocks by the traders. Many landless day labourers found that their wages suddenly no longer sufficed to buy the bare minimum of food. In its analysis of the famine, the colonial administration ignored these hypotheses and antecedent conditions. Had they used the correct hypotheses and observed the relevant facts, the colonial administration could have fought

Giddens A (1995) Politics, Sociology and Social Theory: Encounters with Classical and Contemporary Social Thought.

2 Cf Sen AK (1981) Poverty and Famines: An Essay on Entitlement and Deprivation. 
the famine with price caps and by ordering the rice merchants to liquidate their stocks, thus preventing the catastrophe.

In an explanation, as in the case of the Bengali famine, the explanandum $(\underline{F})$ is known whilst the correct hypotheses and the relevant antecedent conditions remain to be found. For a forecast, by contrast, the explanans (the antecedent conditions and legal hypotheses) is assumed to be known, and the explanandum $(F)$ is what we are looking for. A criminal investigator can explain someone's death by proving that the person drank a cup of tea with a certain amount of cyanide (antecedent condition) and that the dose of poison was lethal (hypothesis). Conversely, if these two statements are true, the person's death can be claimed, regardless of whether a body has been found. Note in this context that the explanandum is derived in the forecast. If the explanandum occurred in the past, one speaks of an ex post forecast. For example, one often tries to assess the scientific value of scientific hypotheses by applying them ex post to predict known past events. For instance, the hypothesis that full employment can be achieved by expanding credit-financed public spending can be tested by examining in different countries whether periods of public credit expansion have reduced unemployment in the past. Since in this constellation the antecedent conditions and the explanandum are well known, a false forecast as an ex post forecast suggests that something is wrong with the legal hypothesis.

Forecasts are always of a conditional nature. They are always subject to the limitation that, firstly, the antecedent conditions that contribute to the event $F$ are fully recorded and precisely formulated and, secondly, the legal hypotheses are valid. Whether the antecedent conditions are fully specified can never be known with certainty. Therefore, future events can never be predicted with certainty, but only conditionally, i.e. subject to the condition of fully specified antecedent conditions. An example: 5 per cent of those who have eaten cooked mussels at a certain restaurant fall ill, and they sue the owner for damages. They can prove that the mussels contained bacteria. The defendant disputes any danger because the mussels were cooked for a sufficiently long time. The court dismisses the action on the grounds of unproven causality. It failed to take into account the antecedence condition that about 5 per cent of the mussels in the pot were not covered by water whilst cooking, so not all germs in them were killed. The incorrectness of the decision is not attributable to false hypotheses but to incompletely ascertained antecedence conditions.

However, incorrect forecasts may be due not only to a failure to consider all relevant antecedent conditions but also to unsuitable legal hypotheses, as illustrated for example by the hypothesis of Lombroso, ${ }^{3}$ according to which people with certain head and ear shapes are criminally inclined. Then, despite the full consideration of all relevant antecedent conditions, a false prognosis regarding a criminal career can ensue. Sometimes such explanatory errors are easy to detect; for example: John does not become pregnant because he is on birth control

Lombroso (1890) Der Verbrecher [The Criminal], Vol. 1 (1894), Vol. 2. To the honour of Lombroso one has to mention that he had the integrity to publicly correct his mistake, once he had identified it. 
pills. Sometimes profound scientific research is necessary to detect the error: Famine is caused by a food availability deficit. ${ }^{4}$

We hold on to the following statement:

\section{Proposition 1.1}

Scientific mis-predictions are based on incorrectly determined or incompletely considered antecedent conditions or on unsuitable hypotheses.

\section{$1.4 \quad$ IMPACT ANALYSIS IN THE JUDGMENT PROCESS}

What is the difference between a scientific forecast and the impact analysis for a legal decision? An appellate court that fundamentally decides a legal problem differs from the scientific forecaster in that in reaching its judgment, it sets an antecedent condition itself, thus influencing the outcome $(F)$. If the judgment furthermore has the effect of deciding similar cases in the same way in the future, it influences future decisions within a legal community. Let $U_{1}$ be the decision to grant the claim, and $U_{2}$ is the decision to dismiss the action.

Given the same and correct antecedent conditions and hypotheses, alternative judgments $\left(U_{1}, U_{2}\right)$ will produce alternative forecasts regarding the outcomes, $F_{1}$ and $F_{2}$.

Let us use a problem from travel law for illustration. Say a vacation day has been spoiled, for example because of a bad room or noise. The alternative $U_{1}$ consists in compensating the holidaymaker with the monetary equivalent of a day's wages and one day's travel expenses if the trip was arranged by a tour operator. In this case, for an impact-based judicial decision, the court must gather information that will enable it to formulate the antecedent conditions, such as:

$A_{1}$ the average cost of holiday accommodation is $€ 200$ per day.

$A_{2}$ the average wage of a holidaymaker is $€ 150$ per day.

In addition to the antecedent conditions that would have to be established in the determination of the facts, there is a further antecedent condition set by the judge himself: the judgment $U_{1 \text { : }}$

$U_{1} \quad$ The defendant tour operator (and in future all tour operators) is liable for spoiled holidays. He must reimburse the cost of the spoiled holiday, plus earnings.

4 In the first example we have used a correct but irrelevant hypothesis, according to which men who take birth control pills do not get pregnant. Cf Woodward J (2009) Scientific Explanation. In: Stanford Encyclopedia of Philosophy. http://plato.stanford.edu/entries/scientific-explanation/. In the second example, a sufficient condition is mistaken for a necessary condition. As shown by Amartya Sen, food availability deficit has been a source of famine only in rare cases during the last 200 years. The hypothesis is incomplete and should correctly be stated as: Famines are always caused, when the real purchasing power of a lot of people is lower than the minimum spending on food. Cf Sen AK (1981) Poverty and Famines: An Essay on Entitlement and Deprivation. 
Furthermore, we have the following legal hypotheses $(G)$ :

$G_{1} \quad$ About 1 per cent of all holidays are spoiled without the tour operator being held liable.

$G_{2}$ Tour operators, through their agents, can influence the choice of their hotels in such a way as to reduce the total number of spoiled holidays.

$G_{3}$ Courts can reliably observe whether a holiday was spoiled.

$G_{4}$ Tour operators maximise their long-term profits.

$G_{5}$ Competition ensures that increases and reductions in costs that affect all companies in an industry equally are fully reflected in price changes.

The following forecast $F_{1}$ can now be derived logically:

1. Since the costs are passed on to consumers $\left(G_{5}\right)$, the prices per holiday day for all holidaymakers who use a tour operator must initially increase by $€ 3.50 .{ }^{5}$

2. Since tour operators maximise their profits $\left(G_{4}\right)$, they will try to reduce their liability costs by improving their choice of hotels, as long as the additional costs incurred are lower than the savings on liability costs. The rate of spoiled holidays will fall below 1 per cent. This will in turn tend to reduce the price, considering the hypothesis of cost changes being passed on to consumers $\left(G_{5}\right)$.

3. The consequence of the judgment $U_{1}$ is thus that the average price of a trip increases and the rate of spoiled holidays declines. This result has been logically derived from the antecedent conditions and the hypotheses. Now assume, by contrast, that the judgment is $U_{2}$ : The tour operator is not liable. Then the result is more spoiled holidays but lower average holiday prices.

Following the identification of alternative consequences, the next step will be the evaluation of these consequences, which we will discuss in Chapter 2. The above impact analysis may be incorrect because the antecedent conditions are inaccurately determined, incorrect or incomplete. For example, the average earnings of vacationers may have been determined incorrectly. This would make the forecast inaccurate. Moreover, the hypotheses could also be wrong, such as the assumption of costs being passed on to consumers or the implicit hypothesis that competition does not force the tour operator to exercise optimal care in the selection of hotels even without liability. In such cases, too, the consequences would be wrongly predicted.

Finally, an error may also have occurred with respect to $G_{3}$ - the assumption that the court can easily ascertain whether a holiday has been spoiled. If the court is prone to mistakes in this regard, injured parties will have an incentive to exaggerate the damage, which again may distort the forecast.

This amount is calculated by multiplying the average cost of accommodation and the average earning of a guest with the number of days of lost holiday. 